\section{Scratching the Armor}

The subdued fluorescent lights in the room fail to illuminate the personal shadow that a 25 -year-old man has created around him. The ubiquitous COVID era mask and gloves further act to make him feel much farther than the five feet difference between the physician and patient chairs. He furtively looks toward the door, wishing he were out of there in the next few seconds, and you squirm in your seat, never having been more uncomfortable.

This is a 25-year-old man with Stage III Hodgkin's lymphoma, having finished four cycles of doxorubicin, bleomycin, vinblastine, dacarbazine protocol, with a positron emission tomography (PET) scan after two cycles showing almost complete disease resolution. This should be good news and a rare moment when patient and doctor both share the same positive tidings. You can see the set of data in front of you, young patient, advanced-stage disease, no specific high-risk features, and good response on PET2: this should translate to a $70 \%-80 \%$ long-term survival. The patient, however, is bogged down by information from the internet. The $20 \%$ risk of relapse looms large in his field of thoughts, and the theoretical risk of secondary malignancies and pulmonary toxicity rears its ugly head. He had plans for the next year, but now it all appears to be going downhill, even as you, as his physician, are disconcerted by this reaction to seemingly good news.

As the patient sheds a quiet tear, you realize how out of your depth this situation is. This is one thing that they never taught you in residency and fellowship. Sure, there was the obligatory session with guidance on how to break bad news and how to empathize, but that was always the 1 hour you could spend not being stressed out about "actual" medical information and patient care. You are unsure of what to do now: should you comfort him? Re-emphasize the "good" news on the PET scan? Tell him that he is lucky to be in the $70 \%-80 \%$ of patients who respond to treatment? Or quote the meme about confusing "my 20 years of experience with 20 min of Google search?"

This is probably the biggest disconnect we see when we compare the slim-figured, golden-haired, long-coated, model-esque oncologists on popular TV with real life. Apart from the flawless golden hair, of course. Have you noted a full episode dedicated to the piano player who might lose his fingers, lumberjack who might not get to use his arms, the mathematician who loses dominant brain function, or a dancer who has a serious muscle disease? This likely serves to emphasize the effect of disease on human beings, magnifying it tenfold by directly affecting the passion/vocation of the protagonist in question. You must have also noted the elderly lady with lymphoma, who spiritedly plans to go to Egypt and the Andes to see ancient ruins and Himalayas to see the Everest. Notice how the doctor spends half an hour each day discussing her plans, reassuring her, and knowing about the names of her children and nephews. If you grew up expecting the same in real life, boy, are you in for a shock! On the other hand, if you are seeing that in real life, wow, tell me how and where.

This disconnect is likely a product of necessity, and it is impossible to have the same depth of clinical responses and emotional stockpile at the same time. Pragmatically, a person can either see 20 (or 50) patients in a time-bound clinic or spend time going into depths of social history and details for two patients. There must be a way to balance it. You hear of old physicians who used to scribble the name of the patient's siblings and pets behind the patient "file," which would be an easy reference during the next visit. Maybe, something similar to that? It is theoretically easier to add such "medically irrelevant" information to a small note in your electronic records for sure. Does it have something to do with the exponential rise in information? A physician now has to deal with history, examination, laboratory tests, radiology, molecular tests, family screening, and ... insurance paperwork. Often relentless, information is fired from all directions, and in many unfortunate cases, on email, phones, and WhatsApp.

We are (a vast majority of us) guilty of the same. And for sure, treating the primary illness is definitely a priority. Scratching beneath the surface is likely to reveal more information than our cognition can handle. Maybe, it is the fear of opening the floodgates, the fear that we won't know when to graciously exit the conversation and divert the attention to medical reports. Maybe, scratching below the surface does have its merits, but we are probably afraid to cut our armor too deep. 


\section{Declaration of patient consent}

The authors certify that they have obtained all appropriate patient consent forms. In the form the patient(s) has/have given his/her/their consent for his/her/their images and other clinical information to be reported in the journal. The patients understand that their names and initials will not be published and due efforts will be made to conceal their identity, but anonymity cannot be guaranteed.

\section{Financial support and sponsorship}

Nil.

\section{Conflicts of interest}

There are no conflicts of interest.

Suvir Singh

Department of Clinical Haematology, Dayanand Medical College and Hospital, Ludhiana, Punjab, India

Address for correspondence: Dr. Suvir Singh, Department of Clinical Haematology, Dayanand Medical College and Hospital, Ludhiana, Punjab, India. E-mail:suvirs@gmail.com
Submitted: 22-Jul-2020

Accepted in Revised Form: 19-Aug-2020

Published: 31-Dec-2020

This is an open access journal, and articles are distributed under the terms of the Creative Commons Attribution-NonCommercial-ShareAlike 4.0 License, which allows others to remix, tweak, and build upon the work non-commercially, as long as appropriate credit is given and the new creations are licensed under the identical terms.

\section{Access this article online}

\begin{tabular}{|l|l|}
\hline \multicolumn{2}{|c|}{ Access this article online } \\
\hline Quick Response Code: & Website: \\
& www.ijmpo.org \\
\cline { 2 - 2 } & DOI: \\
\hline
\end{tabular}

How to cite this article: Singh S. Scratching the armor. Indian J Med Paediatr Oncol 2020;41:893-4. 